\title{
Sliding Mode Control of a Grid-Connected Brushless Doubly Fed Induction Generator
}

\author{
Oussama Moussa $^{1 *}$, Rachid Abdessemed ${ }^{1}$, Said Benaggoune ${ }^{1}$, Hani Benguesmia ${ }^{2}$ \\ ${ }^{1}$ LEB Laboratory, Department of Electrical Engineering, Faculty of Technology, University of Batna 2, Batna 05000, Algeria \\ ${ }^{2}$ LGE Laboratory, Department of Electrical Engineering, Faculty of Technology, University of M'sila, M'sila 28000, Algeria
}

Corresponding Author Email: o.moussa@univ-batna2.dz

https://doi.org/10.18280/ejee.210504

Received: 9 July 2019

Accepted: 22 September 2019

\section{Keywords:}

brushless doubly fed induction generator (BDFIG), vector control, active and reactive power, back-to-back converter, sliding mode control

\begin{abstract}
This paper designs an indirect power control method for brushless doubly fed induction generator (BDFIG), in which the stator is attached to grid with back-to-back space vector modulation (SVM) converter that converts the generated wind power. Our control method is a sliding mode control based on the theory of variable structure control. Specifically, the active and reactive powers, which are exchanged between the stator of the BDFIG and the grid in a linear and decoupled manner, are subjected to decoupled, vector control. In addition, a proportional integral (PI) controller was implemented to keep the DC-voltage constant for the back-to-back SVM converter. The efficiency of our control strategy was validated through simulation. The research greatly promotes the control of renewable energy generators.
\end{abstract}

\section{INTRODUCTION}

Researchers have long searched for alternative form of energy production due to the operational cost and environmental concerns which has led to an increase study of renewable form of energy. Over time, along with the modernization of these renewable forms, a certain complexity has emerged so as for the control strategies $[1,2]$. That is why the Brushless Doubly Fed Induction Generator (BDFIG) based wind energy conversion system (WECS) has recently gained popularity due to his ability to function at variable wind speed achieving an optimal power generation $[3,4]$.

The Brushless doubly fed induction generators (BDFIG) is proven useful for the wind-power generation as the absence of a brush gear improves the performance of the device and it decreases the maintenance cost [5]. This configuration is very useful for offshore and difficult- to-reach installations. In addition, comparing to the DFIG, the BDFIG has less manufacturing cost [6]. This is due to the absence of the slip ring system as well as the simple structure of the rotor winding [7]. Researchers have shifted their focus lately to removing the slip ring and brushes; at the same time, keeping the benefits of the DFIG. Many BDFIG scalar control algorithm are proposed in literature; for example, it is presented that open-loop control, closed loop frequency control and phase-angle control can are capable to stabilizing the machine over a wide range of speed. Nevertheless, the vector control (VC) methods or the field oriented control can offer better dynamic performance [7, 8]. The latter can be used with a conventional proportional and integral (PI) controller as proposed by Poza et al. [9] and Mesbahi et al. [10]. The basis of these control proposals is Taylor's linearization of the system dynamic model around a particular operational point, meaning that the switching of the controller can only be in restricted operational area. However, the following controllers are not robust against parameters differences, model uncertainties and external perturbation; it can also present an asymptotic convergence. The simple implementation of these controllers remains a useful feature in addition to the low computational cost.

Many controls strategies of BDFIG that are based on WECS have been developed recently. We mention: fuzzy logic controller, adaptive controller, variable structure controller and vector controller $[6,7,11,12]$. A potential design could be the combinations of some already mentioned techniques along with other nonlinear approaches [13]. Despite the fact that implementing the nonlinear controllers along with nonlinear systems is very recognized, the control laws that are produced come with a high computational burden. These calculations usually rely on the system states and on many model parameters that have the side effect of minimizing the control robustness [14].

The BDFIG based WECS control strategies composes two independent controls which are: (a) SSC control; (b) GSC control. We propose in this paper a stator side converter sliding mode control with the implementation of active and reactive power of the stator of BDFIG as its input for the stator side converter (SSC), whereas the traditional PI based control strategy governs the grid side converter. Lyapunov stability theory is used to control the stator active and reactive power default despite the fact that this technique is robust against parameters variations, exogenous perturbation and model uncertainties.

\section{THEORY OF OPERATION}

The (BDFIG) brushless doubly fed generator also called the automatic cascade machine composed of two stator windings each with different pole numbers $\left(\mathrm{P}_{\mathrm{p}} \neq \mathrm{P}_{\mathrm{c}}\right)$ for the purpose of avoiding magnetic coupling, and a costumed rotor that couples stator fields which is the nested-loop type of rotor [9].

The power winding (PW) which is the first one is linked to the main, whereas the second one is called the control winding (CW) is supplied with a partially rated power electronics converter as presented in Figure 1. The stator angular 


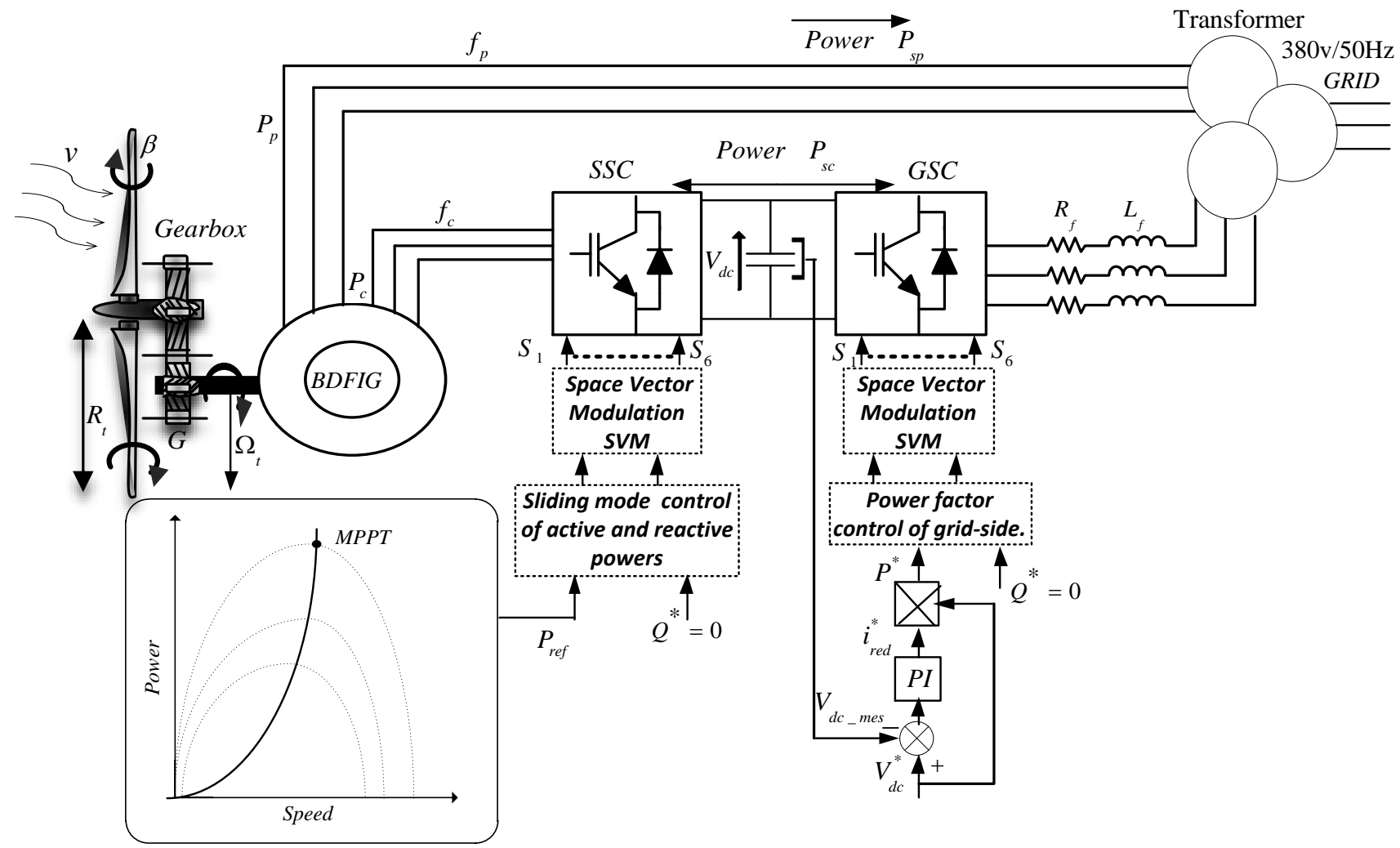

Figure 1. Configuration of BDIFG wind energy

Each of the two stator power supply has a distinct frequency. The first one has a fixed frequency which is linked to the grid through a switch whereas the second power supply has a variable frequency derived from an electronic power frequency converter as presented in Figure 1. If the frequencies of the stator and rotor current are respectively given $\operatorname{asf}_{\mathrm{p}}$ andf $_{\mathrm{c}}$, then the machine natural synchronous speed is equal to [5]:

$$
N_{r}=P_{c}+P_{p}
$$

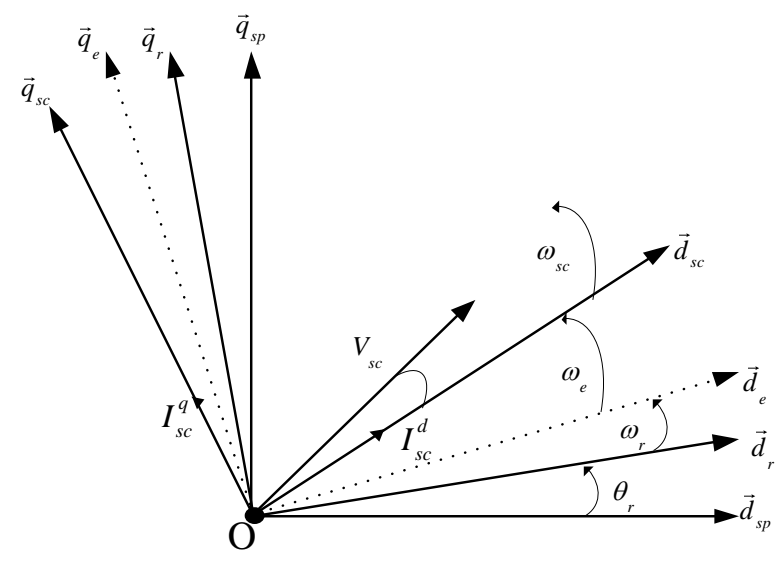

Figure 2. Different reference frame in BDFIG

where, $\omega_{\mathrm{sp}}$ and $\omega_{\mathrm{sc}}$ are the electrical angular velocities of the PW and CW voltages, and $\omega_{r}$ is the rotor angular speed. Pp and $\mathrm{Pc}$ are the number of pole pairs of $\mathrm{PW}$ and $\mathrm{CW}$ respectively, in this case $\mathrm{P}_{\mathrm{p}}=3$ and $\mathrm{P}_{c}=1$, and $\mathrm{Nr}$ is the number of rotor bars. The \pm sign accounts for the case which the $\mathrm{CW}$ is excited in positive or negative phase sequence as presented in Figure 2.

\section{SYSTEM MODELING}

\subsection{Mathematical model of BDFIG}

The electrical equations of the BDFIG in the Park $(d, q)$ reference frame given in Figure 2, that rotates synchronously with the power winding stator flux by angular speed of $\omega_{\text {sp }}[5$, 8 ] is given as:

$$
\begin{gathered}
\mathrm{v}_{s p}=R_{s p} i_{s p}+\frac{d}{d t} \psi_{s p}+j \omega_{s p} \psi_{s p} \\
\mathrm{v}_{s c}=R_{s c} i_{s c}+\frac{d}{d t} \psi_{s c}+j\left(\omega_{s p}-\left(p_{P}+p_{c}\right) \omega_{r}\right) \psi_{s c} \\
\mathrm{v}_{r}=R_{r} i_{r}+\frac{d}{d t} \psi_{r}+j\left(\omega_{s p}-p_{P} \omega_{r}\right) \psi_{r}
\end{gathered}
$$

The flux equations are as follow:

$$
\psi_{s p}=L_{s p} i_{s p}+M_{p} i_{r}
$$




$$
\begin{gathered}
\psi_{s c}=L_{s c} i_{s c}+M_{c} i_{r} \\
\psi_{r}=L_{r} I_{r}+M_{c} i_{s c}+M_{p} i_{s p}
\end{gathered}
$$

The electromagnetic torque is as follow [12]:

$$
T_{e m}=\frac{3}{2}\left[P_{p} M_{p}\left(i_{s p}^{q} i_{r}^{d}-i_{s p}^{d} i_{r}^{q}\right)-\frac{3}{2} P_{c} M_{c}\left(i_{s c}^{q} i_{r}^{d}-i_{s c}^{d} i_{r}^{q}\right)\right]
$$

The stator power's expressions are given as:

$$
\begin{gathered}
P_{s p}=\frac{3}{2}\left(\mathrm{v}_{s p}^{d} i_{s p}^{d}+\mathrm{v}_{s p}^{q} i_{s p}^{q}\right) \\
Q_{s p}=\frac{3}{2}\left(\mathrm{v}_{s p}^{q} i_{s p}^{d}-\mathrm{v}_{s p}^{d} i_{s p}^{d}\right)
\end{gathered}
$$

We conclude from Eqns. (6) and (8) the following:

$$
\begin{gathered}
i_{s p}=\frac{\psi_{s p}-M_{p} i_{r}^{d_{r}}}{L_{s p}} \\
I_{r}=\frac{\psi_{r}-M_{p} I_{s p}-M_{c} I_{s c}}{L_{r}}
\end{gathered}
$$

The substitution of Eq. (13) in Eq. (8) resulted in Eq. (14):

$$
I_{s p}=\frac{L_{r}}{L_{s p} L_{r}-M_{p}^{2}} \psi_{s p}-\frac{M_{p}}{L_{s p} L_{r}-M_{p}^{2}} \psi_{r}+\frac{M_{c} M_{p}}{L_{s p} L_{r}-M_{p}^{2}} i_{s c}
$$

The substitution of Eq. (12) in Eq. (8) and (9) resulted in Eq. (13):

$$
\begin{gathered}
P_{s p}=\frac{3}{2} \mathrm{v}_{s p}\left(\lambda_{5} \psi_{s p}^{q}-\lambda_{4} \psi_{r}^{q}+\lambda_{3} i_{s c}^{q}\right) \\
Q_{s p}=\frac{3}{2} \mathrm{v}_{s p}\left(\lambda_{5} \psi_{s p}^{d}-\lambda_{4} \psi_{r}^{d}+\lambda_{3} i_{s c}^{d}\right)
\end{gathered}
$$

where,

$$
\begin{aligned}
& \lambda_{1}=\frac{L_{s p} M_{c}}{L_{r} L_{s p}-M_{p}^{2}}, \lambda_{2}=L_{s c}-\frac{L_{s p} M_{c}^{2}}{L_{r} L_{s p}-M_{p}^{2}}, \lambda_{3}=\frac{M_{c} M_{p}}{L_{r} L_{s p}-M_{p}^{2}} \\
& \lambda_{4}=\frac{M_{p}}{L_{r} L_{s p}-M_{p}^{2}}, \lambda_{5}=\frac{L_{r}}{L_{r} L_{s p}-M_{p}^{2}}
\end{aligned}
$$

We conclude from Eqns. (4) to (16) that the dynamic relation between the $\mathrm{CW}$ current and the voltage in the voltage in the $\mathrm{d}-\mathrm{q}$ axis $\left(\mathrm{V}_{\mathrm{sc}}\right.$ and $\left.\mathrm{I}_{\mathrm{sc}}\right)$ is given as follow:

$$
\left\{\begin{array}{l}
\mathrm{v}_{s c}^{d}=R_{s c} d_{s c}^{d}+\left(\frac{d}{d t}\left(\lambda_{1} \psi_{r}^{d}+\lambda_{2} i_{s c}^{d}\right)-\omega_{s c}\left(\lambda_{1} \psi_{r}^{q}+\lambda_{2} i_{s c}^{q}-\lambda_{3} \psi_{s p}^{q}\right)\right) \\
\mathrm{v}_{s c}^{q}=R_{s c} i_{s c}^{q}+\left(\frac{d}{d t}\left(\lambda_{1} \psi_{r}^{q}+\lambda_{2} i_{s c}^{q}\right)+\omega_{s c}\left(\lambda_{1} \psi_{r}^{d}+\lambda_{2} i_{s c}^{d}-\lambda_{3} \psi_{s p}^{d}\right)\right)
\end{array}\right.
$$

\subsection{Modeling and control of the grid side converter}

The grid side converter has proven very beneficial as it permits control of active power by preserving constant DClink voltage, it also sets the reference reactive power to zero so iy wouldn't impair the quality of the grid in other words achieving unity power factor, In addition to power bidirectionality $[10,16]$.

Figure 3 demonstrates the structure of a three-phase SVM rectifier, which can be divided into three parts: The source, the converter and the load. The model of the system is given by the following equation:

$$
L_{f} \frac{d}{d t}\left[\begin{array}{c}
i_{f a} \\
i_{f b} \\
i_{f c}
\end{array}\right]=-R_{f}\left[\begin{array}{c}
i_{f a} \\
i_{f b} \\
i_{f c}
\end{array}\right]+\left[\begin{array}{c}
v_{f a} \\
v_{f b} \\
v_{f c}
\end{array}\right]-\left[\begin{array}{c}
v_{s a} \\
v_{s b} \\
v_{s c}
\end{array}\right]
$$

Using switching function, the DC capacitor voltage equation is expressed as follows

$$
C_{d c} \frac{d}{d t} V_{d c}=S_{a} i_{f a}+S_{a} i_{f b}+S_{a} i_{f c}-i_{L}
$$

The active and reactive power control strategy for BDFIG is described through the power winding current. The control winding current $\mathrm{d}-\mathrm{q}$ is composed of the flux-oriented reference frame which can be controlled linearly by a regulator proportional integral (PI) [16]. The aims are to control both the converter on the grid side and the DC link voltage to a specific reference value. In order to achieve this, the DC link voltage should be measured and set to a reference value, and the reference reactive should be kept at zero in order to provide a unit power factor [17].

When applying the park transform on the system $(18,19)$, the model of the converter will be in synchronous reference $d$ $\mathrm{q}$ at the common connection point (CCP) as given:

$$
\left\{\begin{array}{l}
v_{s d}=R_{f} i_{f d}+L_{f} \frac{d i_{f d}}{d t}-L_{f} \omega_{s} i_{f q}+v_{f d} \\
v_{s q}=R_{f} i_{q}+L_{f} \frac{d i_{f q}}{d t}+L_{f} \omega_{s} i_{f d}+v_{f q} \\
C_{d c} \frac{d}{d t} V_{d c}=S_{d} i_{f d}+S_{q} i_{f q}
\end{array}\right.
$$

The DC-link voltage is regulated by the quadratic axis current whereas the reactive power is regulated by the direct axis current. The reference frame is oriented through the stator voltage vector which allows for independent control of the active and reactive power between the GSC and the supply side [18].

Current feed-back values $L_{f} \omega_{s} i_{f q}$ and $L_{f} \omega_{s} i_{f d}$ are given as compensation components in order to cancel the current couple between d-axis and q-axis as well as the disturbance of grid voltage.

The expressions of the active and reactive powers are presented as: 


$$
\left\{\begin{array}{l}
P_{s}=\frac{3}{2}\left[v_{s d} \cdot i_{f d}+v_{s q} \cdot i_{f q}\right] \\
Q_{s}=\frac{3}{2}\left[v_{s q} \cdot i_{f q}-v_{f d} \cdot i_{f q}\right]
\end{array}\right.
$$

The following matrix form demonstrates the given system:

$$
\left[\begin{array}{c}
P_{s} \\
Q_{s}
\end{array}\right]=\frac{3}{2}\left[\begin{array}{cc}
v_{s d} & v_{s q} \\
v_{s q} & -v_{s d}
\end{array}\right]\left[\begin{array}{c}
i_{f d} \\
i_{f q}
\end{array}\right]
$$

The active and reactive powers of references are as follow $\left(\mathrm{P}_{\mathrm{s}}^{*}, \mathrm{Q}_{\mathrm{s}}^{*}\right)$.

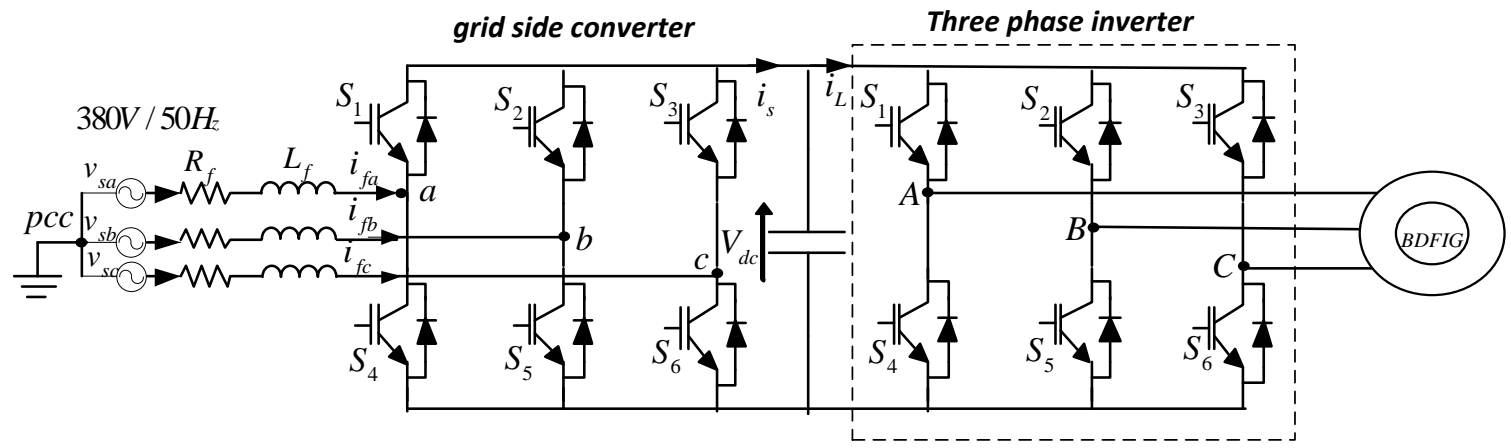

Figure 3. Structure of the back-to-back SVM converter for BDFIG

The reference currents $\left(i_{f d}^{*}, i_{f q}^{*}\right)$ are given by the Eq. (23):

$$
\left[\begin{array}{c}
i_{f d}^{*} \\
i_{f q}^{*}
\end{array}\right]=\frac{2}{3\left(v_{s d}^{2}+v_{s q}^{2}\right)}\left[\begin{array}{cc}
v_{s d} & v_{s q} \\
v_{s q} & -v_{s d}
\end{array}\right]\left[\begin{array}{c}
P_{s}^{*} \\
Q_{s}^{*}
\end{array}\right]
$$

The reference of the real power $\mathrm{P}_{\mathrm{s}}^{*}$ is calculated from the DC bus control loop responsible of maintaining constant DC capacitor voltage. Its value is demonstrated by the given expression:

$$
\left\{\begin{array}{l}
P_{s}^{*}=V_{d c}^{*} . i_{s} \\
Q_{s}^{*}=0
\end{array}\right.
$$

Figure 4 shows the block diagram of the control of the network-side converter.

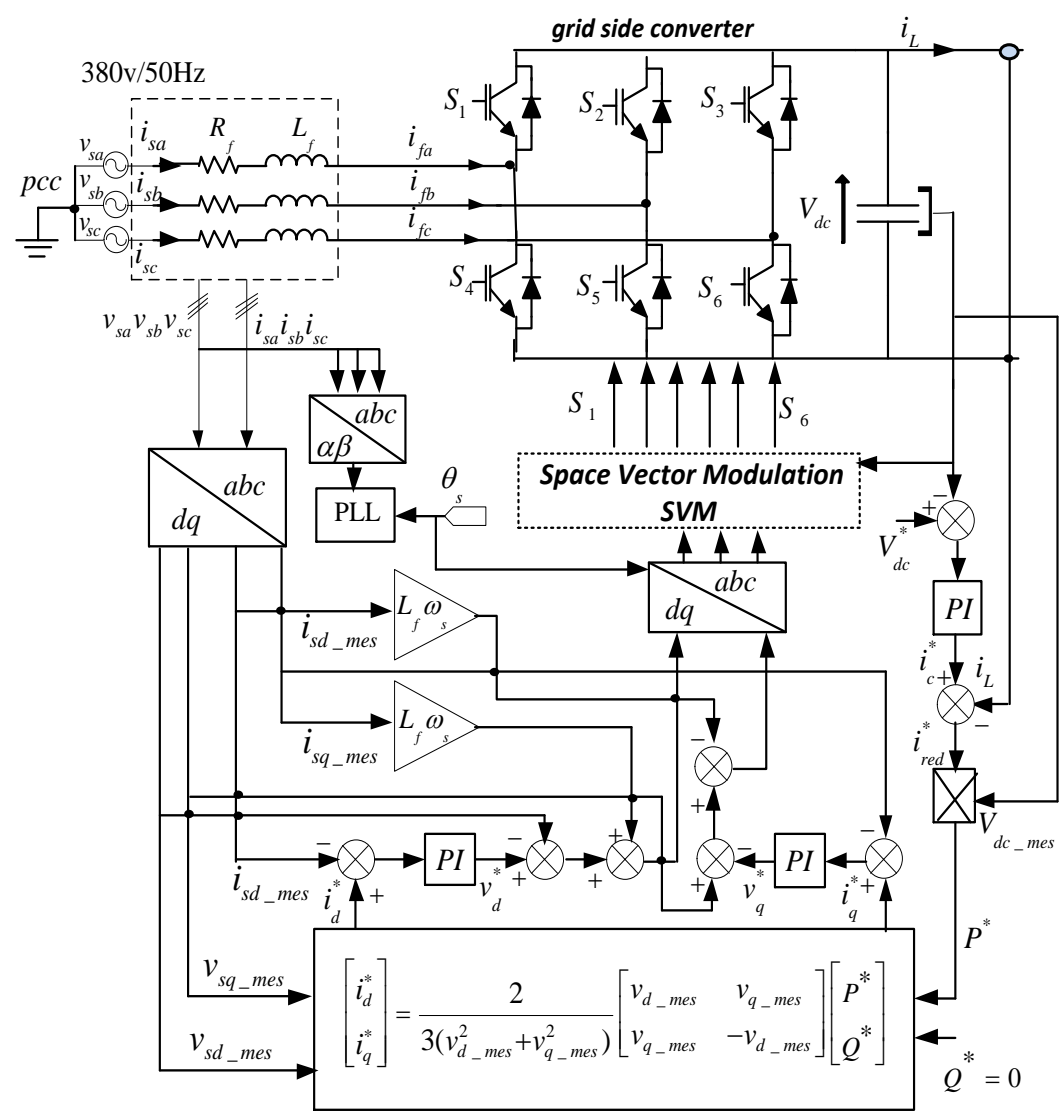

Figure 4. Block diagram of the grid side SVM converter control 


\subsection{Modeling of stator (CW) side converter}

The stator side converter $(\mathrm{CW})$ is implemented to manage the active and reactive powers that are injected by the stator (PW) of the BDFIG into the grid. Whereas the converter implements a simple three-phase inverter with two levels controlled by the Space Vector Modulation technique (SVM) (Figure 3).

$$
\left[\begin{array}{l}
\mathrm{V}_{\mathrm{A}} \\
\mathrm{V}_{\mathrm{B}} \\
\mathrm{V}_{\mathrm{C}}
\end{array}\right]=\frac{V_{d c}}{3}\left[\begin{array}{llr}
2 & -1 & -1 \\
-1 & 2 & -1 \\
-1 & -1 & 2
\end{array}\right]\left[\begin{array}{l}
S_{a} \\
S_{b} \\
S_{c}
\end{array}\right]
$$

\section{STATOR FLUX ORIENTED CONTROL STRATEGY OF THE BDFIG}

Vector control permits the independent control of the flow of active and reactive powers between the grid and generator [19]. The following section describes the function of the vector control technique.

We use the modeling of the generator (see the equation of 1 to 12$)$. We orient the reference $(d, q)$ so that the axis $d$ is aligned with the stator flux of the $\psi_{s p}$ power generator.

We will assume that the d-axis of park mark is oriented according to the stator flux, this choice is justified by the fact that the generator is often coupled to a powerful network of constant voltage and frequency.

The dynamic equations is simplified in a big scale due to the orientation following the flow of the PW since the value of $\left|\psi_{s p}\right|$ set approximately constant, which results is the terms that have the $\frac{d\left|\psi_{s p}\right|}{d t}$ factor are almost null [5].

We use the modeling of the generator (see the equation of 1 to 12$)$. We orient the reference $(d, q)$ so that the axis $\mathrm{d}$ is aligned with the stator flux of the $\psi_{s p}$ power generator.

With constant and oriented stator flux

$$
\left\{\begin{array}{l}
\psi_{s p}^{d}=\left|\psi_{s p}\right| \\
\psi_{s p}^{q}=0
\end{array}\right.
$$

The stator flux equation of the generator $(\mathrm{PW})$ becomes:

$$
\left\{\begin{array}{l}
\psi_{s p}^{d}=L_{s p} i_{s p}^{d}+M_{p} i_{r}^{d} \\
0=L_{s p} i_{s p}^{q}+M_{p} i_{r}^{q}
\end{array}\right.
$$

For the purpose of simplifying calculations, the stator voltage constraint can be given as Eq. (23) in the d q-axis.

$$
\left\{\begin{array}{l}
\mathrm{v}_{s p}^{d}=0 \\
\mathrm{v}_{s p}^{q}=\mathrm{v}_{s p}
\end{array}\right.
$$

Replacing Eqns. (18) and (16) in Eqns. (13 and 14), the power expressions turn to:

$$
\left\{\begin{array}{l}
P_{s p}=\frac{3}{2} \mathrm{v}_{s p}^{q}\left(-\lambda_{4} \psi_{r}^{q}+\lambda_{3} i_{s c}^{q}\right) \\
Q_{s p}=\frac{3}{2} \mathrm{v}_{s p}^{q}\left(\lambda_{5} \psi_{s p}^{d}-\lambda_{4} \psi_{r}^{d}+\lambda_{3} i_{s c}^{d}\right)
\end{array}\right.
$$

\section{DESIGN OF SLIDING MODE CONTROL (SMC)}

The control techniques are enhanced and improved to enable the controlled system to be robust and stable taking into consideration the parametric variations, and external disturbances. These control techniques offer a fast dynamic response and an error, between the set point and the desired output, zero steady state [14]. The order by sliding mode control is proffered due to its simplicity and robustness. This is a discontinuous command that requires controllers with variable structure.

A system with variable structure is a system whose structure shifts throughout its functioning. The selection of structure and switching logic permits the system to switch from one structure to another at any chosen moment. The benefit of the variable structure control with the sliding mode is the robustness in front of variations of the internal parameters of the system and the parameters of the exterior perturbations [20].

One related to the system discussed by the next state space equation:

$$
[\dot{X}]=[A][X]+[B][U]
$$

With, $[X] \in R^{n}$ is the state vector $[U] \in R^{m}$ is the control input vector; $[A]$ and $[B]$ are system parameter origins.

The number one stage of the control design is contained from choosing the number of the switching surface $s(x)$. Mainly, the number of sliding surfaces is selected equal to the dimension of the control vector $[U]$.

The sliding surface is essentially tackled in the following general form:

$$
s(x)=\left(\frac{d}{d t}+\lambda\right)^{r-1} e(x)
$$

where, $\lambda$ is a strictly positive constant; guarantee controllability; $e(x)=X^{r e f}-X$ is the error variable. The aim is to keep $s(x)=0$. Therefore, force the dynamics of the deviation (reference - output) to be a dynamic of an autonomous linear system of order $r$, with respecting the condition of convergence. These conditions permit the various dynamics of the system to converge on the sliding surface and to be kept free from the perturbation [21]

$$
\dot{s}(x) s(x) \prec 0
$$

As the sliding regime arrives at the dynamics of the system, an appropriate control is needed to captivate the state trajectory to the surface and after that to its point of stabilization while ensuring the conditions of existence of the sliding mode. For that, the structure of this order has two parts:

$$
U(t)=U_{e q}+\Delta U
$$


$U_{e q}$ Regarding the exact linearization which is a similar command fundamental to keep the variable to be controlled on the sliding surface $s(x)$.

The derivative of the surface $s(x)$ is:

$$
\begin{gathered}
\dot{s}(x)=\frac{d s}{d t}=\frac{\partial s}{\partial x} \frac{\partial x}{\partial t} \\
\dot{s}(x)=\frac{d s}{d t}=\frac{\partial s}{\partial x}\left\{[A][X]+[B] U_{e q}\right\}+\frac{\partial s}{\partial t}[B] \Delta U
\end{gathered}
$$

Throughout the sliding mode and the stable state, the surface is null and as a result its derivative and the ending part are also zero. Consequently, we conclude the expression of the equivalent command.

$$
U_{e q}=-\left\{\frac{\partial s}{\partial x}[B]\right\}^{-1}\left\{\frac{\partial s}{\partial x}[A][B]\right\}
$$

With: $\frac{\partial s}{\partial x}[B] \neq 0$

Throughout the convergence mode, the $\Delta U \neq 0$ changing (31) in to (30), yields

$$
\dot{s}(x)=\frac{\partial s}{\partial X}[B] \Delta U
$$

Changing (37) in to (32), we have:

$$
s(x) \frac{\partial s}{\partial X}[B] \Delta U \prec 0
$$

In order for the state trajectory is captivated by the switching surface $s(x)=0$.

$\Delta U$ Stable, this is necessary to eliminate model printing impacts and to reject exterior perturbations.

$$
\Delta U=k_{x} \operatorname{sign} s(x)
$$

where, $k_{x}$ decides the ability of controlling the chattering [5].

An integral action is now joined to the control so it can decrease the gain of the "sign" function and then decrease the chattering impact. This action is also going to enhance the controller's performances in terms of reference tracking [22]. The integral surface form is presented as:

$$
\zeta=k_{i} \int_{0}^{t} s(t) d t
$$

The integral function is joined throughout the positive stage of the sliding surface, the equivalent control will have the following form:

$$
U(t)=U_{e q}+\Delta U+\zeta
$$

\section{INDIRECT POWER CONTROL WITH SMC OF A BDFIG}

In this segment, the sliding surfaces are recognized based on the active and the reactive power references presented in the Eq. (14). The main aim of this design is to independently control the active and reactive generated powers.

\section{A. Choice of the sliding surfaces}

The showed relation between the current $(\mathrm{CW})$ and the power (PW) are gathered as follow:

$$
\left\{\begin{array}{l}
i_{s c}^{d}=\frac{Q_{s p}}{1.5 \mathrm{v}_{s p}^{q} \cdot \lambda_{3}}+\frac{\lambda_{4}}{\lambda_{3}} \psi_{r}^{d}-\frac{\lambda_{5}}{\lambda_{3}} \psi_{s p}^{d} \\
i_{s c}^{q}=\frac{P_{s p}}{1.5 \mathrm{v}_{s p}^{q} \cdot \lambda_{3}}+\frac{\lambda_{4}}{\lambda_{3}} \psi_{r}^{q}
\end{array}\right.
$$

We have:

$$
\left\{\begin{array}{l}
i_{s c}^{d-r e f}=\frac{Q_{s p}^{r e f}}{1.5 \mathrm{v}_{s p}^{q} \cdot \lambda_{3}}+\frac{\lambda_{4}}{\lambda_{3}} \psi_{r}^{d}-\frac{\lambda_{5}}{\lambda_{3}} \psi_{s p}^{d} \\
i_{s c}^{q-r e f}=\frac{P_{s p}^{r e f}}{1.5 \mathrm{v}_{s p}^{q} \cdot \lambda_{3}}+\frac{\lambda_{4}}{\lambda_{3}} \psi_{r}^{q}
\end{array}\right.
$$

SMC robust strategy is applied in order to ensure the current $(\mathrm{CW})$ and the $(\mathrm{PW})$ convergence to their references. The showed surfaces are presented as follow:

$$
\left\{\begin{array}{l}
s\left(P_{s p}\right)=\left(i_{s c}^{q-r e f}-i_{s c}^{q}\right) \\
s\left(Q_{s p}\right)=\left(i_{s c}^{d-r e f}-i_{s c}^{d}\right)
\end{array}\right.
$$

\section{B. Conditions of convergence}

To guarantee the convergence of chosen variables towards the references, the two slip surfaces must be null as following:

$$
\left\{\begin{array} { l } 
{ s ( i _ { s c } ^ { q - r e f } - i _ { s c } ^ { q } ) = 0 } \\
{ s ( i _ { s c } ^ { d - r e f } - i _ { s c } ^ { d } ) = 0 }
\end{array} \Rightarrow \left\{\begin{array}{l}
\frac{d}{d t}\left(i_{s c}^{q-r e f}-i_{s c}^{q}\right)=0 \\
\frac{d}{d t}\left(i_{s c}^{d-r e f}-i_{s c}^{d}\right)=0
\end{array}\right.\right.
$$

The realization of a sliding mode is conditioned by the verification by the attractiveness of Lyaponov: $\dot{s}(x) s(x)<0$ and the surface time invariance $\dot{s}(x)=0$. To control the current, we take $(r=1)$, then the derivative of the surface is presented by the following

$$
\left\{\begin{array}{l}
\dot{s}\left(P_{s p}\right)=\left(\dot{i}_{s c}^{q-r e f}-\dot{i}_{s c}^{q}\right) \\
\dot{s}\left(Q_{s p}\right)=\left({\dot{i_{s c}}}^{d-r e f}-\dot{i}_{s c}^{d}\right.
\end{array}\right)
$$

From Eq. (17), the derivate of control current $\left(I_{S c}^{\dot{d}}, I_{s c}^{\dot{q}}\right)$ can be described as:

$$
\left\{\begin{array}{l}
\frac{d}{d t}\left(i_{s c}^{d}\right)=\frac{\mathrm{v}_{s c}^{d}}{\lambda_{2}}-\frac{R_{s c}}{\lambda_{2}} i_{s c}^{d}+\frac{\omega_{s c}}{\lambda_{2}}\left(\lambda_{1} \psi_{r}^{q}+\lambda_{2} i_{s c}^{q}\right)-\frac{\lambda_{1}}{\lambda_{2}} \dot{\psi}_{r}^{d} \\
\frac{d}{d t}\left(i_{s c}^{q}\right)=\frac{\mathrm{v}_{s c}^{q}}{\lambda_{2}}-\frac{R_{s c}}{\lambda_{2}} i_{s c}^{q}-\frac{\omega_{s c}}{\lambda_{2}}\left(\lambda_{1} \psi_{r}^{d}+\lambda_{2} i_{s c}^{d}-\lambda_{3} \psi_{s p}^{d}\right)-\frac{\lambda_{1}}{\lambda_{2}} \psi_{r}^{q}
\end{array}\right.
$$


Changing the current expression (43) into (42), we have:

$$
\left\{\begin{array}{l}
\dot{s}\left(P_{s p}\right)=\left(\dot{i}_{s c}^{q_{-} r e f}-\left[\frac{\mathrm{v}_{s c}^{q}}{\lambda_{2}}-\frac{R_{s c}}{\lambda_{2}} i_{s c}^{q}-\frac{\omega_{s c}}{\lambda_{2}}\left(\lambda_{1} \psi_{r}^{d}+\lambda_{2} i_{s c}^{d}-\lambda_{3} \psi_{s p}^{d}\right)\right]-\frac{\lambda_{1}}{\lambda_{2}} \psi_{r}^{q}\right) \\
\dot{s}\left(Q_{s p}\right)=\left(\dot{i}_{s c}^{d_{-} r e f}-\left[\frac{\mathrm{v}_{s c}^{q}}{\lambda_{2}}-\frac{R_{s c}}{\lambda_{2}} i_{s c}^{q}+\frac{\omega_{s c}}{\lambda_{2}}\left(\lambda_{1} \psi_{r}^{q}+\lambda_{2} i_{s c}^{q}\right)-\frac{\lambda_{1}}{\lambda_{2}} \psi_{r}^{d}\right]\right)
\end{array}\right.
$$

So we can guarantee the captivation of the system towards the surface, the following condition must be reached out:

$$
s\left(P_{s p}, Q_{s p}\right) s\left(P_{s p}, Q_{s p}\right)<0
$$

C. Development of the control laws

The algorithm of control is known by the relation:

$$
\left\{\begin{array}{l}
\mathrm{v}_{s c}^{d}=\mathrm{v}_{s c}^{d-e q}+\mathrm{v}_{s c}^{d-a t t r} \\
\mathrm{v}_{s c}^{q}=\mathrm{v}_{s c}^{q-e q}+\mathrm{v}_{s c}^{q-a t t r}
\end{array}\right.
$$

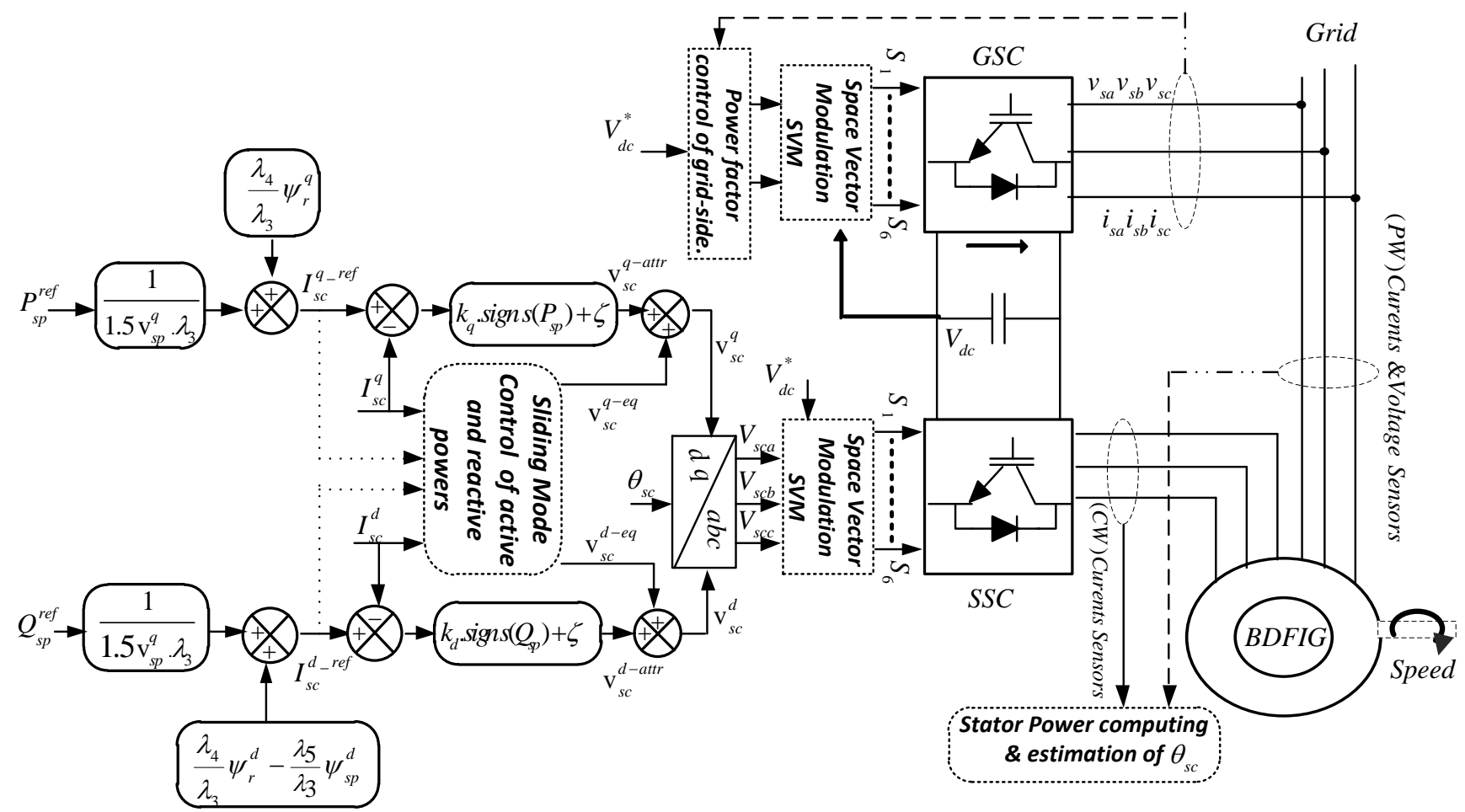

Figure 5. Block diagram of BDFIG control scheme

\section{SIMULATION OUTCOMES}

The control strategy proposed in this study has been accepted by the Matlab/Simulink software. The fundamental parameters of BDIGF simulation model are tackled in Table number 1. For that reason, the results accomplished are properly ordered based on the given specifications in which the speed is balanced at $(600 \mathrm{tr} / \mathrm{min})$. The distinction of the active power is between $-1500 \mathrm{~W},-2500 \mathrm{~W}$ and $-2000 \mathrm{~W}$ respectively at $2 \mathrm{~s}$ and $3.5 \mathrm{~s}$, in the meantime the reactive power is balanced at 0 var. Figure 6 shows the performances of SMC of the active and reactive powers stator, from where the good tracking of theirs set points can be detected clearly which reflect the acceptable dynamics of the system, responding to $\mathrm{v}_{s c}^{d}, \mathrm{v}_{s c}^{q}:$ is the control vector.

$\mathrm{v}_{s c}^{d-e q}, \mathrm{~V}_{\mathrm{sc}}^{\mathrm{q}-\mathrm{eq}}:$ is the equivalent control vector.

$\mathrm{V}_{\mathrm{Sc}}^{\mathrm{d}-\mathrm{attr}}, \mathrm{v}_{s c}^{q-a t t r}$ : is the switching part of the control.

The equivalent control winding $(\mathrm{CW})$ voltage vector is showed by

$$
\left\{\begin{array}{l}
\mathrm{v}_{s c}^{q-e q}=\lambda_{2} \dot{i}_{s c}^{q-r e f}+\left(R_{s c} i_{s c}^{q}+\omega_{s c}\left(\lambda_{1} \psi_{r}^{d}+\lambda_{2} i_{s c}^{d}-\lambda_{3} \psi_{s p}^{d}\right)+\lambda_{1} \psi_{r}^{q}\right) \\
\mathrm{v}_{s c}^{d-e q}=\lambda_{2} \dot{i}_{s c}^{d-r e f}+\left(R_{s c} i_{s c}^{q}-\omega_{s c}\left(\lambda_{1} \psi_{r}^{q}+\lambda_{2} i_{s c}^{q}\right)+\lambda_{1} \psi_{r}^{d}\right)
\end{array}\right.
$$

For that reason, the switching term is delivered by:

$$
\left\{\begin{array}{l}
\mathrm{v}_{s c}^{q-a t t r}=k_{q} \cdot \operatorname{sign} s\left(P_{s p}\right)+\zeta \\
\mathrm{v}_{s c}^{d-a t t r}=k_{d} \cdot \operatorname{sign} s\left(Q_{s p}\right)+\zeta .
\end{array}\right.
$$

The BDFIG global sliding-mode control are illustrated in Figure 5. 
these outcomes show the robustness (Figure 10) of the structure of control against an 100\% changing of the (CW and PW)resistances; even though a small disturbance can be detected, it does not have a notable impact on the stator active and reactive responses (figures zoom, respectively).

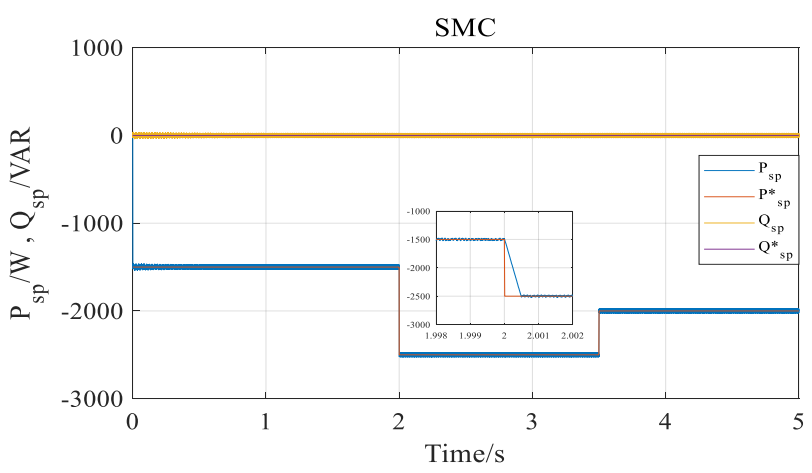

Figure 6. Stator (PW) active and reactive power
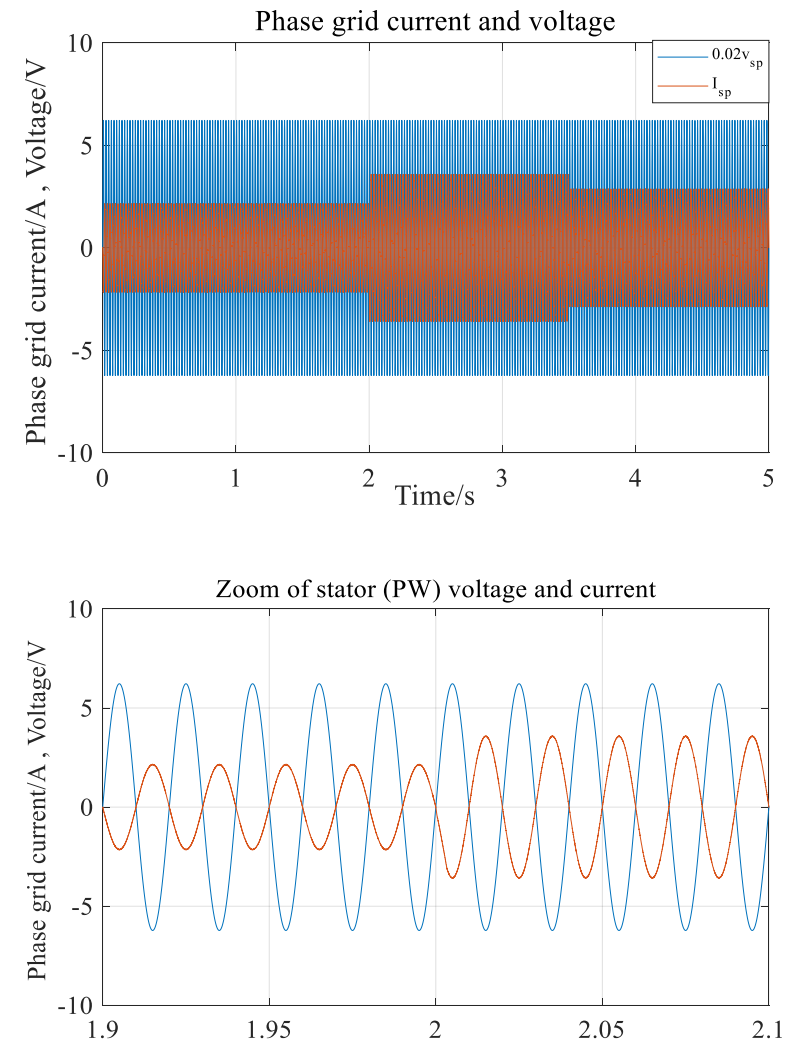

Figure 7. Stator $(\mathrm{PW})$ voltage and current

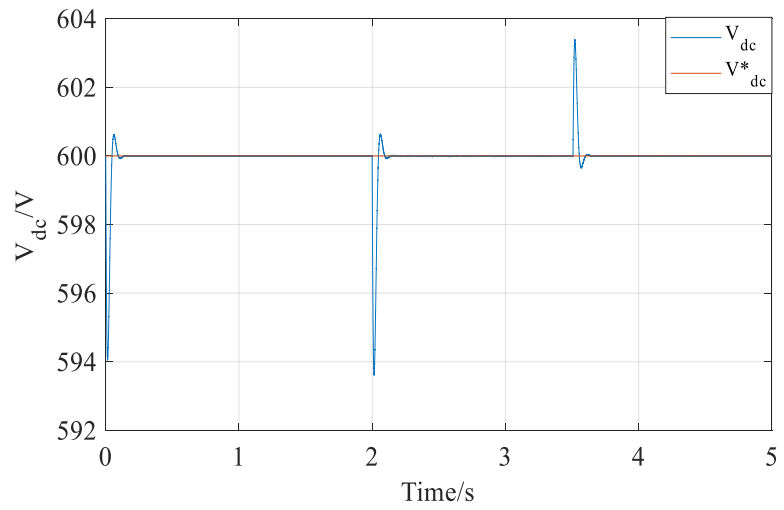

Figure 8. DC bus voltage
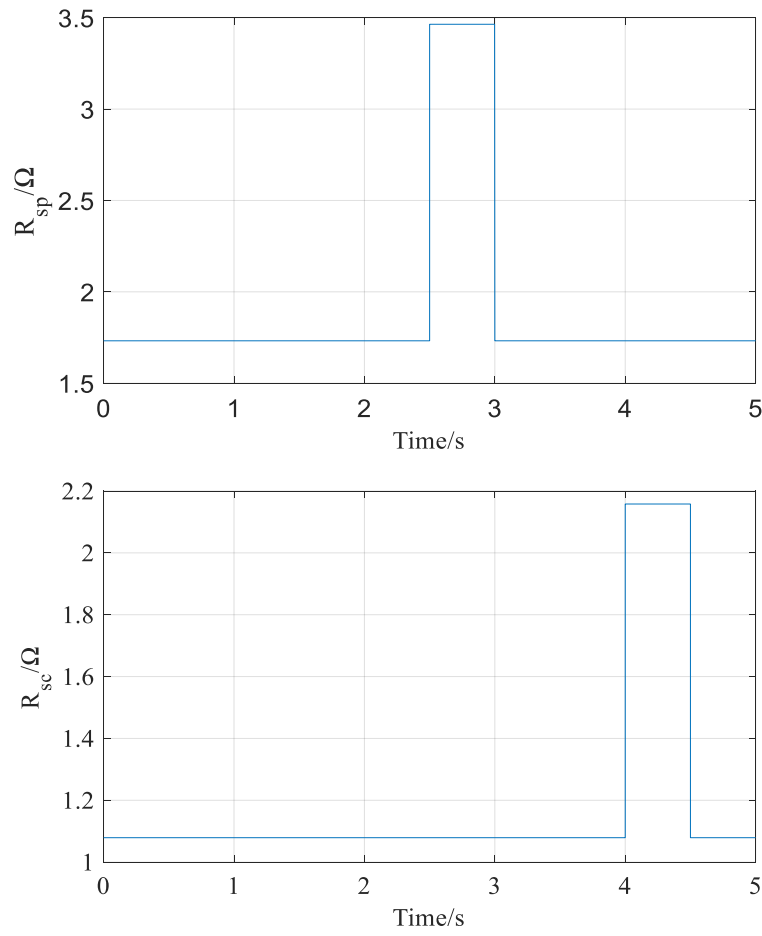

Figure 9. Parameter variations

a) Vector control
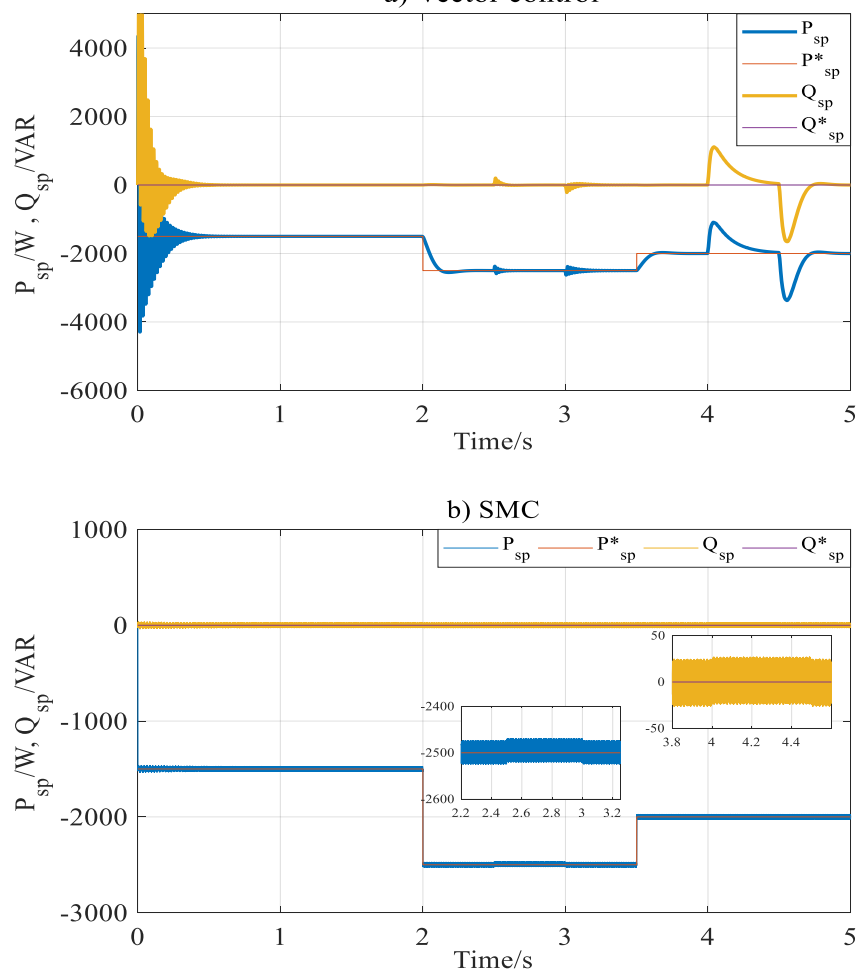

Figure 10. Stator $(\mathrm{PW})$ active and reactive power response (a) Vector control; (b) SMC

Table 1. Electrical parameters of prototype BDFIG for simulation

\begin{tabular}{ccc}
\hline Power winding $(\mathbf{P W})$ & Control Winding $(\mathbf{C W})$ & Rotor \\
\hline$R_{s p}=1.732$ & $R_{s c}=1.079$ & $R_{r}=0.473$ \\
$L_{s p}=714.8$ & $L_{s c}=121.7$ & $L_{r}=132.6$ \\
$M_{p}=242.1$ & $M_{c}=59.8$ & \\
$P_{p}=3$ & $P_{c}=1$ & \\
\hline
\end{tabular}


The parameters of Back-to-back SVM converter used in our study:

Input $\mathrm{AC}$ rated phase-voltage $\mathrm{Vinp}=220 \mathrm{~V} / \mathrm{f}=50 \mathrm{~Hz}$, DC link capacitance: $\mathrm{C}=0.0022 \mathrm{f}, \mathrm{AC}$ filter inductance: $L_{f}=0.02 \mathrm{H}$; resistance $R_{f}=0.1 \Omega$.

\section{CONCLUSIONS}

The BDFIG double accessibility is highly significant advantage. This encourages good control of the power flow between machine and grid allowing implanting the power such that the grid power factor is closed to unity. In this study, robust vector control planned for the BDFIG has been explored. The stability of the robust control has been proven using the sliding mode controller. This method is valuable in the way that it clarifies the procedure of the BDFIG design which resulted in the stability and the robustness decoupling control of the active and reactive powers of the BDFIG linked to the grid. The robustness test is accomplished in two ways in order to verify the structure of the control used, where instantaneous set-point variations of the active and reactive powers and a test by switching of the (PW and CW) resistances have been applied. So the found outcomes have presented the ability of the adopted structure of control as the good set-point tracking without any registered impact, and the good robustness in contrast to the parameters changing have been noticed. Simulation outcomes show high performance of the granted control strategy with the verification of the parameter error and external disturbances. By decoupling the system, this approach improves its performance. In addition to the control strategy guarantees the zero performance of the transient system with decrement of the stabilization time. As a conclusion we say that suggested BDFIG system control is an unusual solution in the wind energy area.

\section{REFERENCES}

[1] Dash, P.K., Patnaik, R.K. (2014). Adaptive second order sliding mode control of doubly fed induction generator in wind energy conversion system. Journal of Renewable and Sustainable Energy, 6(5): 053143 http://dx.doi.org/10.1063/1.4899193

[2] Tamaarat, A., Benakcha, A. (2014). Performance of PI controller for control of active and reactive power in DFIG operating in a grid-connected variable speed wind energy conversion system. Frontiers in Energy, 8(3): 371-378. https://doi.org/10.1007/s11708-014-0318-6

[3] Fateh, L., Ahmed, O., Amar, O., Abdelhak, D., Lakhdar, B. (2016). Modeling and control of a permanent magnet synchronous generator dedicated to standalone wind energy conversion system. Frontiers in Energy, 10(2): 155-163. https://doi.org/10.1007/s11708-016-0410-1

[4] Cheikh, R., Menacer, A., Chrifi-Alaoui, L., Drid, S. (2018). Robust nonlinear control via feedback linearization and Lyapunov theory for permanent magnet synchronous generator-based wind energy conversion system. Frontiers in Energy, 1-12. https://doi.org/10.1007/s11708-018-0537-3

[5] Mahboub, M.A., Drid, S., Sid, M.A., Cheikh, R. (2017). Sliding mode control of grid connected brushless doubly fed induction generator driven by wind turbine in variable speed. International Journal of System
Assurance Engineering and Management, 8(2): 788-798. https://doi.org/10.1007/s13198-016-0524-1

[6] Serhoud, H., Benattous, D. (2013). Sensorless optimal power control of brushless doubly-fed machine in wind power generator based on extended Kalman filter. International Journal of System Assurance Engineering and Management, 4(1): 57-66. https://doi.org/10.1007/s13198-012-0141-6

[7] Shao, S., Abdi, E., Barati, F., McMahon, R. (2009). Stator-flux-oriented vector control for brushless doubly fed induction generator. IEEE Transactions on Industrial Electronics, 56(10): https://doi.org/10.1109/TIE.2009.2024660

[8] McMahon, R.A., Wan, X., Abdi-Jalebi, E., Tavner, P.J., Roberts, P.C., Jagiela, M. (2006). The BDFM as a generator in wind turbines. In 12th International Power Electronics and Motion Control Conference, pp. 18591865. https://doi.org/10.1109/EPEPEMC.2006.4778676

[9] Poza, J., Oyarbide, E., Roye, D., Rodriguez, M. (2006). Unified reference frame DQ model of the brushless doubly fed machine. IEE Proceedings Electric Power Applications, 153(5): 726-734. https://doi.org/10.1049/ip-epa:20050404

[10] Mesbahi, T., Ouari, A., Ghennam, T., Berkouk, E.M., Mesbahi, N. (2016). A hybrid wind energy conversion system/active filter for non linear conditions. International Journal of System Assurance Engineering and Management, $\quad 7(1)$ : $1-8$. https://doi.org/10.1007/s13198-014-0250-5

[11] Xia, C., Guo, H. (2015). Feedback linearization control approach for brushless doubly-fed machine. International Journal of Precision Engineering and Manufacturing, 16(8): 1699-1709. https://doi.org/10.1007/s12541-0150223-X

[12] Mahboub, M.A., Drid, S., Sid, M.A., Cheikh, R. (2016). Robust direct power control based on the Lyapunov theory of a grid-connected brushless doubly fed induction generator. Frontiers in Energy, 10(3): 298-307. https://doi.org/10.1007/s11708-016-0411-0

[13] Hu, J., Nian, H., Hu, B., He, Y., Zhu, Z.Q. (2010). Direct active and reactive power regulation of DFIG using sliding-mode control approach. IEEE Transactions on Energy Conversion, 25(4): 1028-1039. https://doi.org/10.1109/TEC.2010.2048754

[14] Ammar, A., Bourek, A., Benakcha, A. (2017). Robust SVM-direct torque control of induction motor based on sliding mode controller and sliding mode observer. Frontiers in Energy, 1-14. https://doi.org/10.1007/s11708-017-0444-z

[15] Williamson, S., Ferreira, A.C. (1997). Generalised theory of the brushless doubly-fed machine. Part 2: Model verification and performance. IEE ProceedingsElectric Power Applications, 144(2): 123-129. https://doi.org/10.1049/ip-epa:19971052

[16] Yao, J., Li, H., Liao, Y., Chen, Z. (2008). An improved control strategy of limiting the DC-link voltage fluctuation for a doubly fed induction wind generator. IEEE Transactions on Power Electronics, 23(3): 12051213. https://doi.org/10.1109/TPEL.2008.921177

[17] Bekakra, Y., Attous, D.B. (2014). DFIG sliding mode control fed by back-to-back PWM converter with DClink voltage control for variable speed wind turbine. Frontiers in Energy, 8(3): 345-354. https://doi.org/10.1007/s11708-014-0330-X 
[18] Payam, A.F., Jalalifar, M. (2006). Robust speed sensorless control of doubly-fed induction machine based on input-output feedback linearization control using a sliding-mode observer. 2006 International Conference on Power Electronic, Drives and Energy Systems,

pp.

$1-5$.

https://doi.org/10.1109/PEDES.2006.344348

[19] Dida, A., Attous, D.B. (2015). Doubly-fed induction generator drive based WECS using fuzzy logic controller. Frontiers in Energy, 9(3): 272-281. https://doi.org/10.1007/s11708-015-0363-9

[20] Levant, A. (1993). Sliding order and sliding accuracy in sliding mode control. International Journal of Control, 58(6): $1247-1263$ https://doi.org/10.1080/00207179308923053

[21] Rahali, H., Zeghlache, S., Benalia, L., Layadi, N. (2018). Sliding mode control based on backstepping approach for a double star induction motor (DSIM). AMSE Journals, Series Advances C, 73(7): 150-157.

[22] Chen, S.Z., Cheung, N.C., Wong, K.C., Wu, J. (2010). Integral sliding-mode direct torque control of doubly-fed induction generators under unbalanced grid voltage. IEEE Transactions on Energy Conversion, 25(2): 356368. https://doi.org/10.1109/TEC.2009.2036249 